\title{
Minimizing Costs of Poor Quality for Glass Container Bottles Production Using Six Sigma's Dmaic Methodology: A Case Study in a Bottle and Glass Share Company
}

\author{
Besufekad Legesse, Sisay Geremew \\ School of Mechanical and Industrial Engineering, Bahir Dar University, Bahir Dar, Ethiopia \\ Email address: \\ lilbesufekad@gmail.com (B. Legesse), sisayg78@gmail.com (S. Geremew) \\ To cite this article: \\ Besufekad Legesse, Sisay Geremew. Minimizing Costs of Poor Quality for Glass Container Bottles Production Using Six Sigma's Dmaic \\ Methodology: A Case Study in a Bottle and Glass Share Company. Industrial Engineering. Vol. 5, No. 1, 2021, pp. 7-20. \\ doi: $10.11648 /$ j.ie. 20210501.12
}

Received: April 26, 2021; Accepted: June 24, 2021; Published: August 23, 2021

\begin{abstract}
Even if many tools are available to reduce defect, six sigma's DMAIC model is one of a tool which significantly reduce defect if it is applied with appropriate methodology. In this work defect reduction is achieved using DMAIC model as a means. At the define phase major product types and defects are crafted and identified by using brainstorming, supplier-inputprocess-output-customer diagram, Pareto Diagram and failure mode and effect analysis. So that poor bead diameter and uneven glass distribution have been selected from the glass making processes. At the measuring phase data has taken and observed to display how the process behaves. Control charts, capability analysis and six pack capability analysis are applied to understand the process condition. Based on the data obtained from the preceding phase analysis undertaken using Fishbone diagram. The graph illustrates the root causes that are in need to improve. After the analysis phase identified the root causes i.e. process parameters, the improvement phase has held by using Taguchi technique to optimize the process parameters. The Taguchi analysis identified the main factors which determine the processes output factors. After the optimum value is decided the result is collected to check its effectiveness. these improvements decreased defects per million opportunities (DPMO) from 149,997.8 to 50,000 and reduced poor quality cost from ETB 429,540.3 to ETB 143,178 per day and the result showed that defect has reduced by $30 \%$ compared with the previous output.
\end{abstract}

Keywords: DMAIC Methodology, Cost of Poor Quality, Six Sigma

\section{Introduction}

Nowadays organizations struggle for an enhanced level of process capability and a reduced amount of cost of poor quality (COPQ), while the ultimate target of those organizations is to create a profit margin and put up with their competitiveness in the market. Then the (COPQ) is the cost associated with the repair, rework, scrap, warranty claims and write-offs from obsolete finished goods [6].

The Six Sigma DMAIC (define, measure, analyze, improve and control) methodology is used to reduce variation and defects in the process. It is a methodology based on datadriven and fact-based analysis to find out the root cause of the problem with the help of statistical analysis [15].

Six sigma is the one of the most powerful management tool used to achieve process excellence. It has been successful in many western companies; most of them are fortune 500 companies like GE, Motorola, and Ford are few of them [14]. The DMAIC model is used when a process or product is in existence but is not meeting the customer requirements. And the DMADV model is used when a process or product is not in existence or is needed to be developed [1]. Six Sigma is a strategic initiative and can be considered by itself as a vehicle for other strategic initiatives [8].

One of the well-known methods to reduce the cost of poor quality is a project-based approach called six sigma DMAIC methodology. This six sigma methodology is used to improve 
present processes and had been verified to be successful in the fields of reducing costs, improving cycle times, eliminating defects raising customer satisfaction [4].

Process improvement and operational cost reduction through quality improvement practices has been at the centre of attention for many businesses in different sizes and in a variety of sectors to gain a more competitive advantage. Lean Six Sigma (LSS) is an effective and disciplined business transformation strategy and problem solving tool that has evolved through the combination of Lean and Six Sigma, both recognized as leading Total Quality Management (TQM) tools for performance improvement in organizations with a proper infrastructure built on leadership and change culture [12]. A fundamental aspect of Six Sigma methodology is the identification of critical-to-quality (CTQ) characteristics that are vital to customer satisfaction [5].

The DMAIC project signifies a structured roadmap used to enhance the existing process, such DMAIC projects struggle to reduce deviation and improve performance about a target, which depicts that each process segment should undergo through a gate review before containing to next. The DMAIC model is a backbone for six sigma implementation and a roadmap to quasi-perfect improvement activities [7].

DMAIC methodology is a step by step method which makes an available pathway to go to the origins of the problems that gives an opening for enhanced performance through governing mechanisms.

\section{Literature Review}

A researcher called [10] has stated that; Even the tool has an esteemed place in the manufacturing arena it does not get a clear and agreeable definition for the past three decades. Many of the definitions of Six Sigma found in the literature are very general and do not provide elements or factors. As well [16] affirms that when we look at Six Sigma as a methodology, there are many models available for process improvements like DMADV, DMAIC, Breakthrough strategy, Eckes method, Six Sigma Roadmap, IDOV, and DMEDI.

According to Six Sigma consultants, a process many have multiple "opportunities" to make a defect. Hence the calculation of DPMO considers the number of opportunities. This means DPMO is not the same as defects per million units (DPMU). DPMO is always lower than DPMU because the number of opportunities is included in the denominator. Using DPMO has some interesting implications [17].

It was first developed in Motorola Company by Dr. Mikel Harry and was called MAIC (acronym of Measure, Analyze, Improve and Control). But when GE tries to exercise the model it didn't exactly know its quality problems and, therefore, first needed to map the real quality problems to solve them. Besides that, GE intended to use Six Sigma for new problems, as soon as they appeared, so the method should also contain the problem identification task. Since the main goal of Six Sigma is reducing defects by minimizing process variation many manufacturing and service giving sector used a tool to achieve customer satisfaction [13]. According to [11] DMAIC approach is the scientific approach for reducing the deviations and improving the capability levels of the manufacturing processes. Textile industries, metal industries, automotive industries, glove industry, software developing companies, education system, healthcare companies are some of the examples which apply six sigma and achieve defect reduction [2]. [9] Have presented different tools for the phases methodologies of DMAIC. Each phases have used from simple to advance tools according to the scope of implementation.

Some of the research questions to be addressed in this research are How to identify major sources of defect making, What are the types of defect mostly occurred in the company, How to measure defect according to their type and machine area the processed, How to analyze the causes for defect occurring, Which counter measure and control mechanisms are suitable for selected defect types.

\section{Case Company Profile}

Addis Ababa Bottle \& Glass Share Company "Addis Glass" Established in 1972 capital Located in Addis Ababa. And has two factories: Factory 1 is the old plant with 35 tons per day $\&$ Factory 2 is the new plant 50 ton per day capacity. Both lines produce labeled glass containers of different sizes and shapes. And has an estimated annual capacity of 9,308 tons.

Furthermore, substituting import Glass materials and take part in the international market and build capacity to generate foreign currency.

\section{Methods of Analysis and Interpretations}

This research is conducted on minimizing of cost of poor quality in Addis Ababa Bottle and Glass Share Company. The researcher used both qualitative and quantitative approaches. The diagnostic feature of this quantitative research is that the techniques used to generate numerical data, which is collected and analyzed mathematically. The research involved vital research strategies to complete it. First, the current situation in the company is observed to gain fundamental information related to productivity level of different areas by performance objective- productivity approach (PO-P) and different causes of defects to bring improvement. 


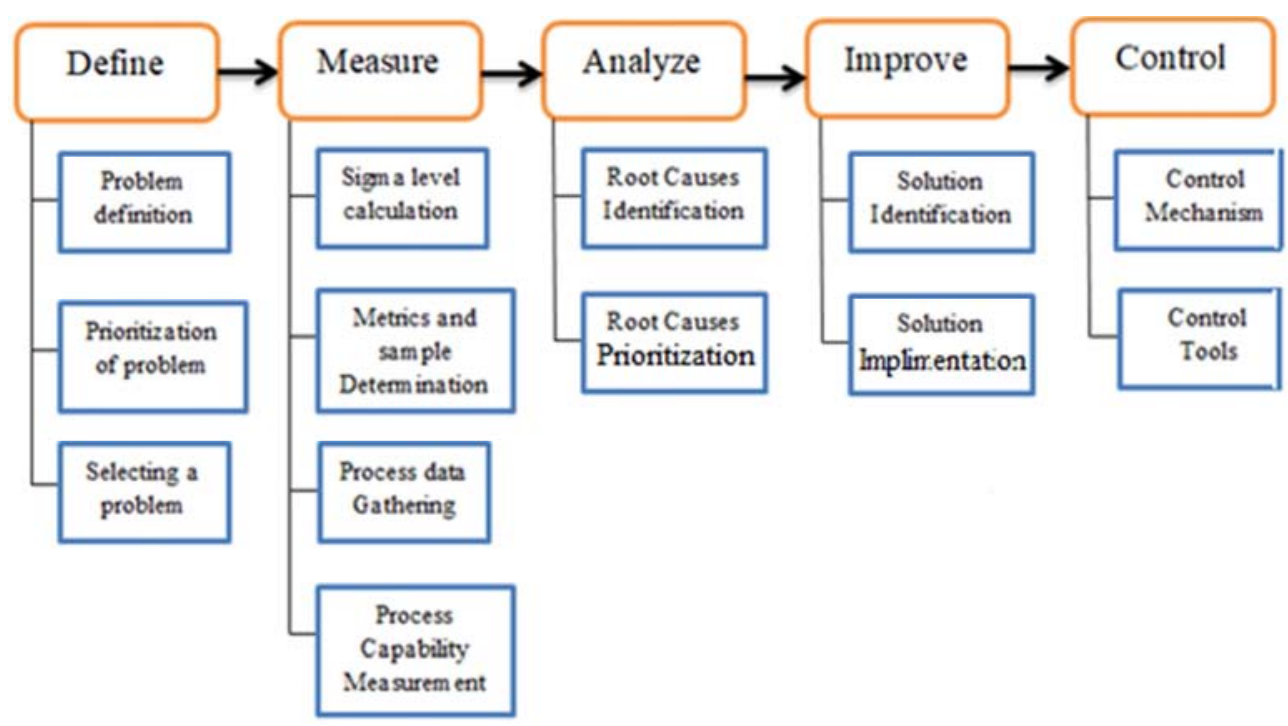

Figure 1. Methodology for DMAIC implementation.

\section{Result and Discussion}

\subsection{Dmaic Results}

\subsubsection{Define}

Focus group has been selected to identify all defect types using their experience. And then through brain storming the focus group members identified 10 defect types which frequently occurred. The data available in quality control department is collected to cross check the identified defect type which happened and registered.

Table 1. Selected types of defects according to their frequency by the focus group.

\begin{tabular}{ll}
\hline Defect type & \\
\hline Mould seam & Shoulder Crack \\
Folding & Unfilled Finish \\
Bottom Crack & Ring Crack \\
Thin Distribution & Poor Bead Diameter \\
Body Crack & Wedged bottom \\
\hline
\end{tabular}

Table 2. Defective product amount per product type for the past six month.

\begin{tabular}{llll}
\hline Type of Product & Total product ton & Total defects, ton & Defects\% \\
\hline Wine Seduction & 914.26 & 500.7058 & $55 \%$ \\
Beer 292 & 678.8 & 97.72 & $14 \%$ \\
Castel Beer 303 & 546.78 & 100.8882 & $18 \%$ \\
Beer 300 & 560.7 & 82.319 & $15 \%$ \\
Arekie & 407 & 61.05 & $15 \%$ \\
Hair Oil \& Zenith & 288.36 & 37.4868 & $13 \%$ \\
\hline
\end{tabular}

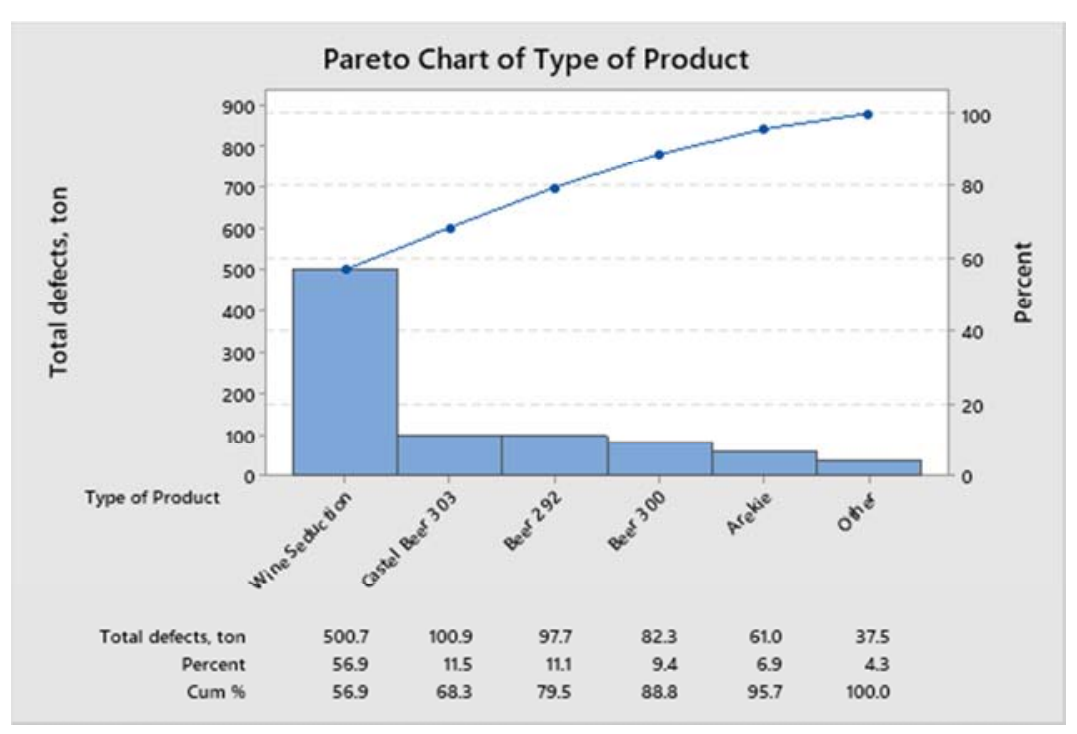

Figure 2. Pareto diagram of defective product amount vs. product type. 
To deal with such an issue Failure Mode and Effect Analysis (FMEA) is a key.

From the data gathered in the above section Poor Bead Diameter and Uneven glass Distribution has a high possibility for improvement. Knowing the cause for occurrence and fixing process parameter will be the next process. For instance, fish bone diagram is helpful/advisable to investigate the cause from the $4 \mathrm{Ms}$ point of view i.e. man, machine, material and method. Firstly, it is important to know each defect behavior and characteristics to understand why it happens constantly.

Table 3. FMEA for selected defect types.

\begin{tabular}{|c|c|c|c|c|c|}
\hline Defect type & Severity & Detectability & Occurrence & RPN & Rank \\
\hline Poor Bead Diameter & 8.75 & 7 & 2.4 & 147 & 1 \\
\hline Folding & 6.5 & 7.5 & 0.3 & 14.625 & 9 \\
\hline Bottom Crack & 7 & 7.5 & 0.7 & 36.75 & 5 \\
\hline Body Crack & 7 & 5 & 1.7 & 59.5 & 3 \\
\hline Uneven Glass Distribution & 8 & 8.5 & 1.15 & 78.2 & 2 \\
\hline Mould seam & 8 & 6 & 0.5 & 24 & 7 \\
\hline Unfilled Finish & 7.5 & 7.5 & 0.6 & 33.75 & 6 \\
\hline
\end{tabular}

It can prioritize defects concerning their occurrence, Detectability and severity. For the process dealt with the focus group identify 10 major defects. which are thin distribution, Poor Bead Diameter, Folding, Bottom Crack, Ring Crack, Shoulder Crack, Body Crack, Wedged bottom and Unfilled Finish.

\subsubsection{Measure}

After defect opportunities are identified it is possible to calculate DPMO of the total process. Knowing DPMO helps to know the sigma level of the process. First amount of defect occurred in the work place should be known. Then test type, opportunities of a product that produces defective product should be identified.

Product Amount per day $=45,454$ bottles

Defect $=45 \%=45,454 * 0.45=20,454.3$ bottles

Opportunity $=3$ (pre-analytical, analytical, post analytical)

$$
\begin{aligned}
\mathrm{DPO}= & \frac{\text { Defect }}{\text { Product } * \text { Opportunities }} \\
& =\frac{20,454.3}{45,454 * 3} \\
& =0.14998
\end{aligned}
$$

Defect Per Million Opportunities (DPMO)

$$
\begin{gathered}
(\mathrm{DPMO})=\frac{\text { Defect }}{\text { Product } * \text { Opportunities }} * 10^{6} \\
=\frac{20,454.3}{45,454 * 3} * 10^{6} \\
=149,997.8
\end{gathered}
$$

Seduction Bottle measurement (Poor Bead Diameter)

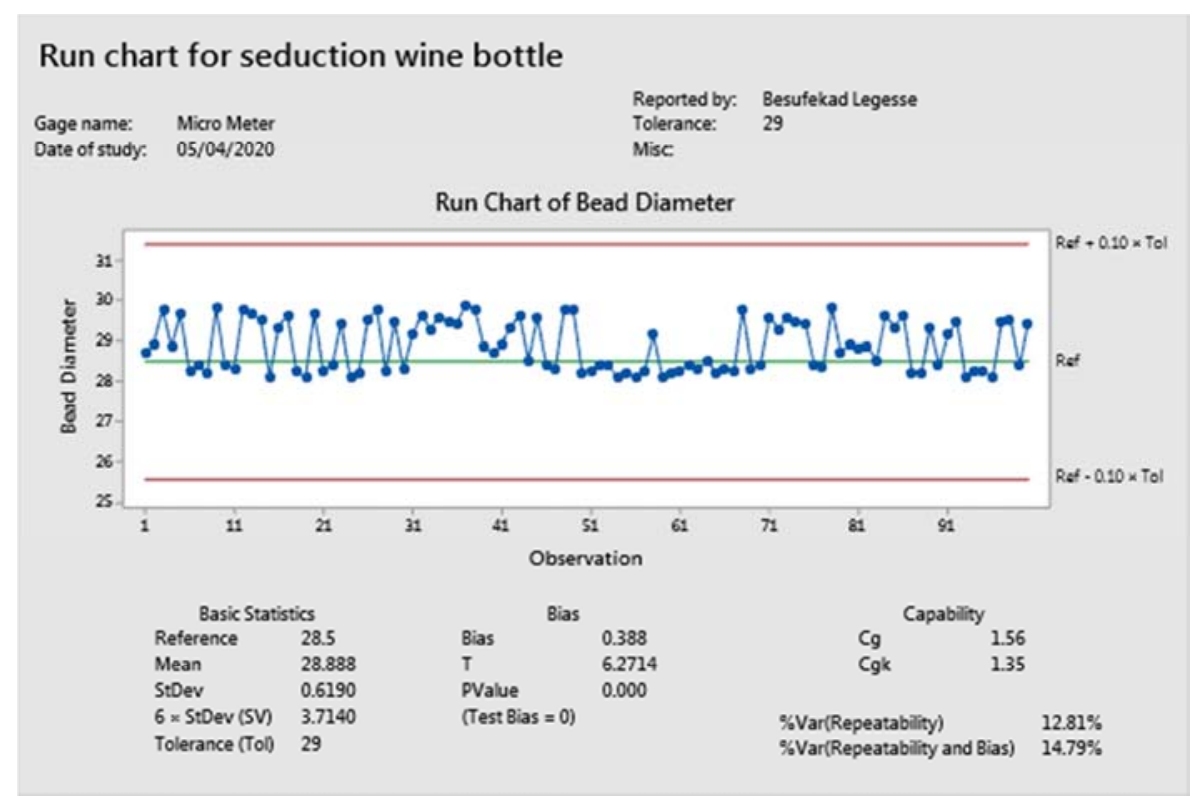

Figure 3. Run Chart for seduction wine bottle.

Bias $=0.388$ shows there is no bias in the measurement system 


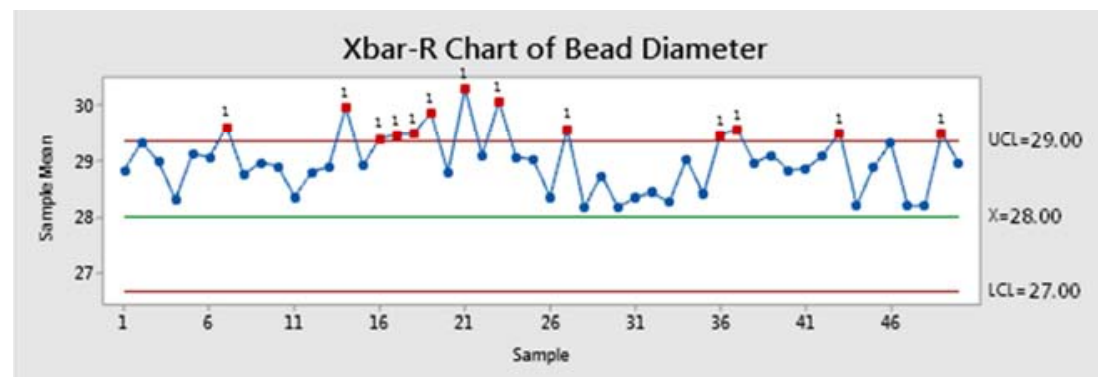

Figure 4. XBar S chart for Bead Diameter in 2 subgroups.

Test Failed at points: 7, 14, 16, 17, 18, 19, 21, 23, 27, 36, $37,43,49$

The figure shows the product is out of control in 13 sample points by using x bar as a reference. Thus the process doesn't fulfill customer's requirement unless some adjustment in the process has done. It also indicates the process variation is significant and there is an assignable/special causes are there in the process.

Conclusion: The process is not capable to meet customer requirement and the need to improve the processes, since this test result indicate that the Process average is unstable and the process is out of control, possibly due to the presence of special causes. Thus it is must to identify and correct the factors contributing to this special-cause variation. Until these causes are eliminated

Castel Beer Bottle measurement

Measuring Thin Distribution (Thin Glass Distribution)

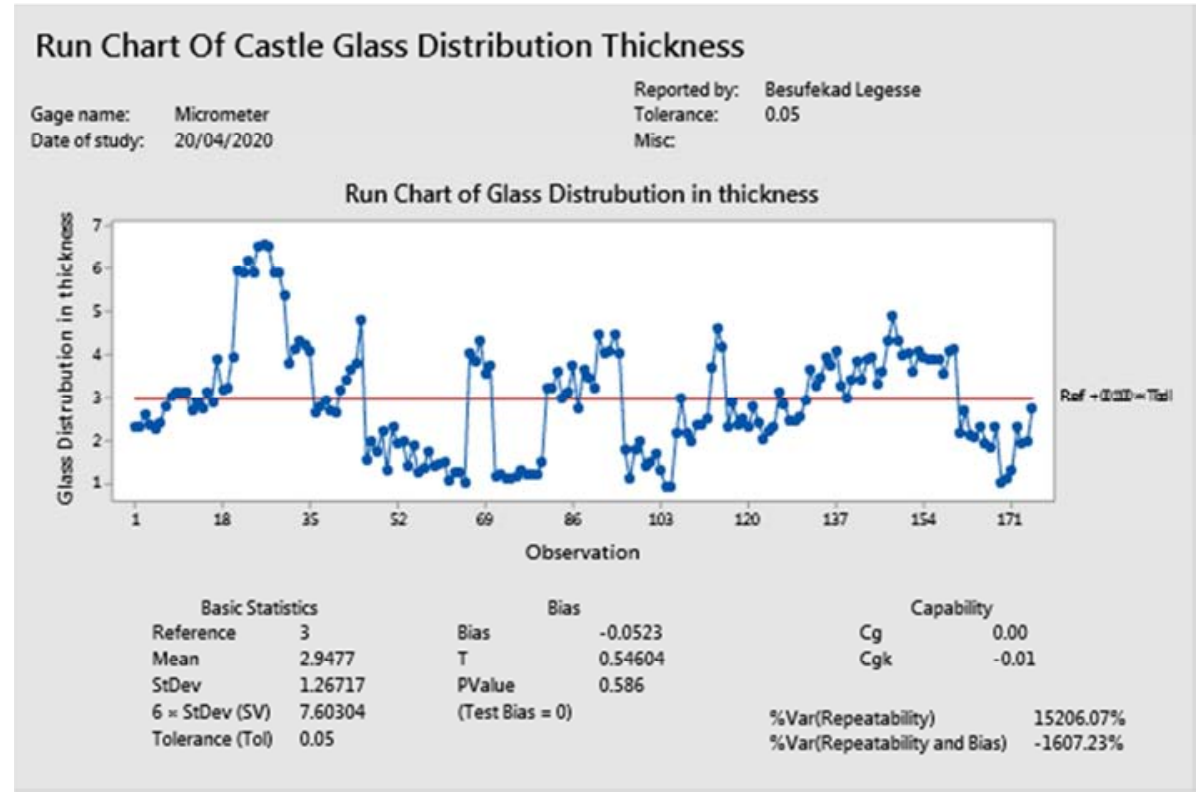

Figure 5. Run chart for Castle Bottle Glass thickness (Type 1 Gage study).

Bias $=-0.0523$ shows there is no bias in the measurement system

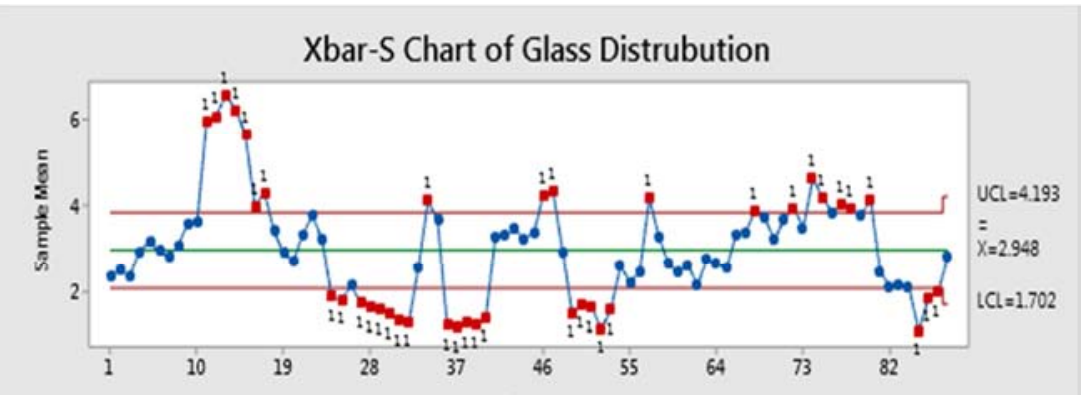

Figure 6. Xbar-S Chart of glass distribution.

Test 1. One point more than 3.00 standard deviations from center line.
Test Failed at points: 11, 12, 13, 14, 15, 16, 17, 24, 25, 27 , $28,29,30,31,32,34,36,37,38,39,40,46,47,49,50,51$, 


\section{$52,53,57,68,72,74,75,77,78,80,85,86,87$.}

The figure shows the product is out of control in 39 out of 175 sample points by using $\mathrm{x}$ bar as a reference. Thus the process doesn't fulfill customer's requirement unless some adjustment in the process has done. It also indicates the process variation is significant and there is an assignable/special causes are there in the process.

Conclusion: The process is not capable to meet customer requirement and the need to improve the processes, since this test result indicate that the Process average is unstable and the process is out of control, possibly due to the presence of special causes. Thus it is must to identify and correct the factors contributing to this special-cause variation. Until these causes are eliminated.

\subsubsection{Analysis}

Analysis on bad or uneven glass distribution (Thickness) for castle bottle.

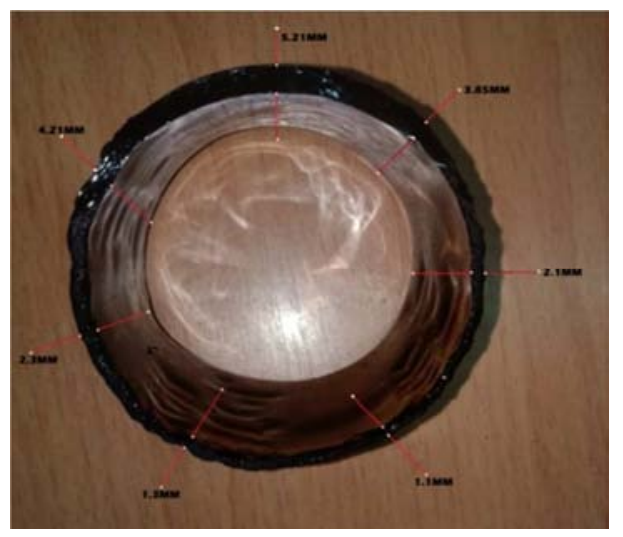

Figure 7. Measurement of thickness (Glass Distribution) for Castle bottle.

$\mathrm{T}=\mathrm{D}_{\mathrm{o}}-\mathrm{D}_{\mathrm{i}}$

$\mathrm{T}$ - thickness,

$\mathrm{D}_{\mathrm{o}}$ - outer diameter,

$\mathrm{D}_{\mathrm{i}}$-inner diameter

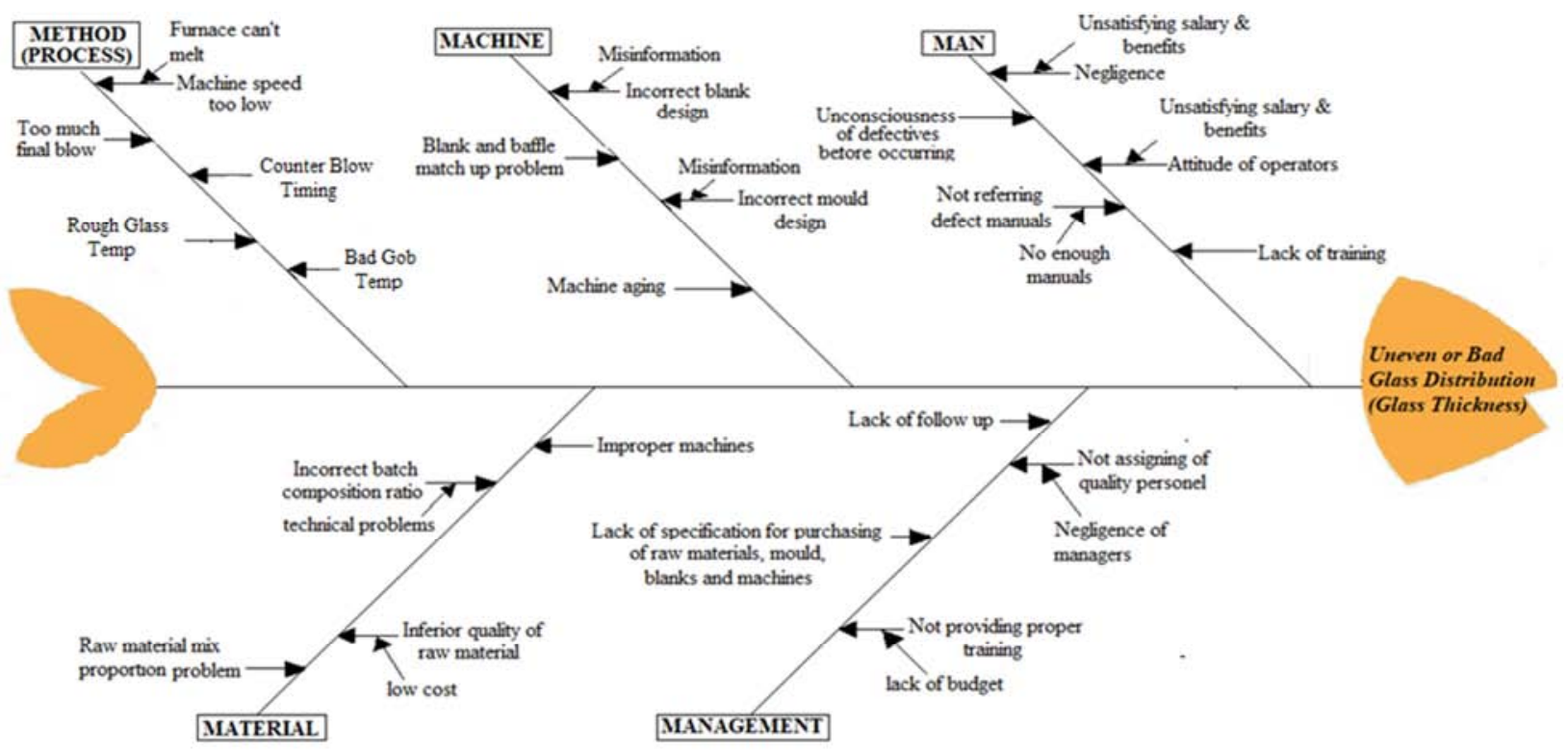

Figure 8. Cause and Effect diagram for uneven or bad glass distribution.

Simplicity: the quality or condition of being easy to understand or do (easy to understand $=1$, difficult to understand $=5$ ).

Occurrence: the fact or frequency of something happening (not repetitively happening=1, repetitively happening=5).

Detectability: The extent to which something is detectable
(Easily detectable=1, Difficult to detect=5).

Impact on Quality: The marked effect or influence of the source on quality (No Impact=1, excessive impact=5).

Controllable: the situation of being under the regulation or domination throughout the process (Easily Controllable $=1$, Difficult to control=5).

Table 4. Criteria (Criteria matrix) to find critical root causes for uneven glass distribution.

\begin{tabular}{llllllll}
\hline \multirow{2}{*}{ Sources } & Criteria & & & & & \multirow{2}{*}{ Sum } \\
\cline { 2 - 6 } & Simplicity & Occurrence & Detectability & Impact on Quality & Controllable & \\
\hline Man & 3 & 4 & 2 & 5 & 5 & 5 & 19 \\
Method (Process) & 4 & 5 & 4 & 5 & 5 & 23 & 1 \\
Machine & 3 & 4 & 4 & 4 & 5 & 20 & 2 \\
Material & 2 & 3 & 3 & 4 & 3 & 15 & 4 \\
Management & 3 & 1 & 2 & 3 & 2 & 5 \\
\hline
\end{tabular}

From the above table, it can be figured out that the process part has a major factor for defect making. So that identifying and optimizing the process parameter will be the next move. 
Analysis on poor bead diameter of Seduction wine bottle

Table 5. Criteria (Criteria matrix) to find critical root causes for poor bead diameter.

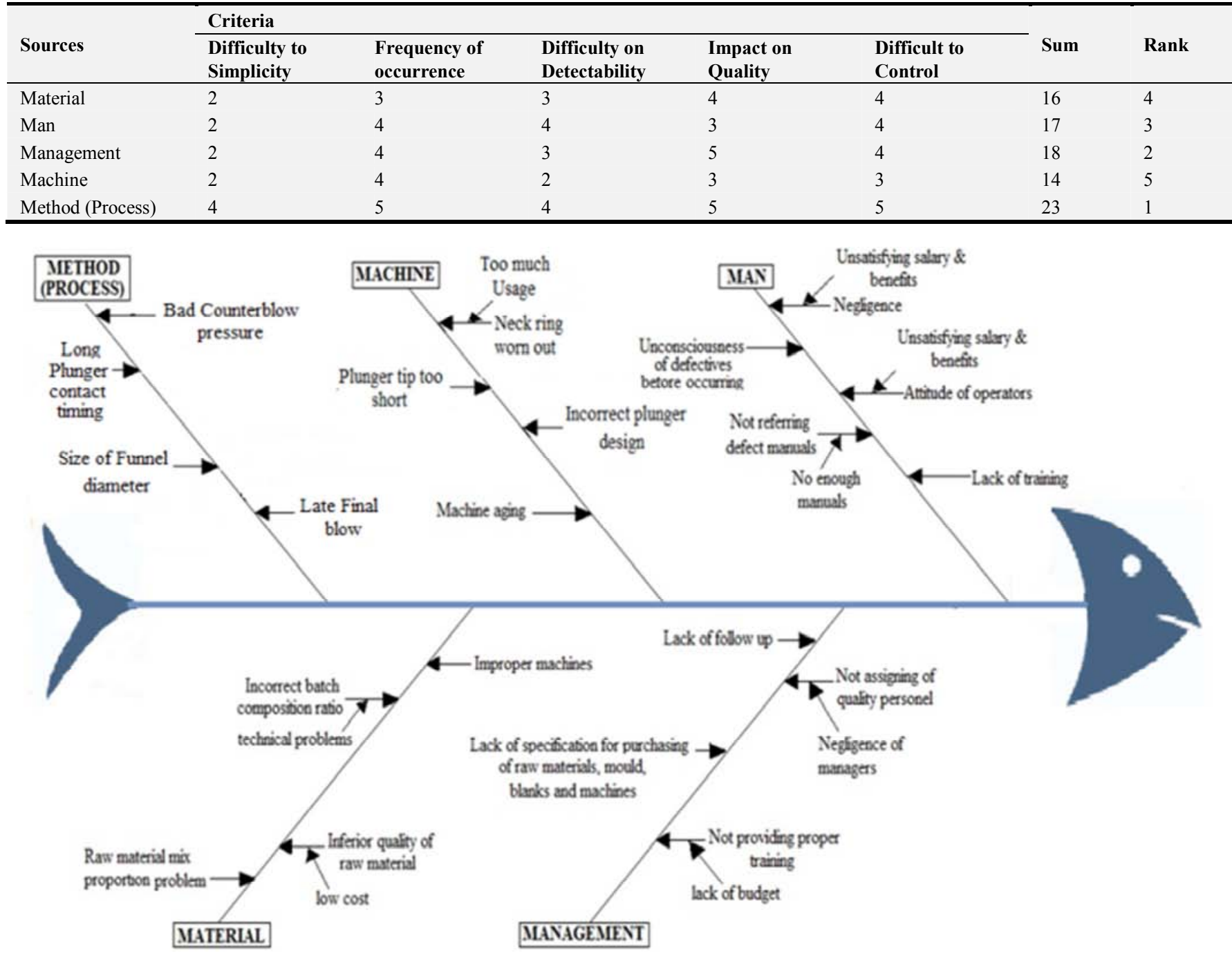

Figure 9. Cause and Effect diagram for poor bead diameter of seduction wine bottle.

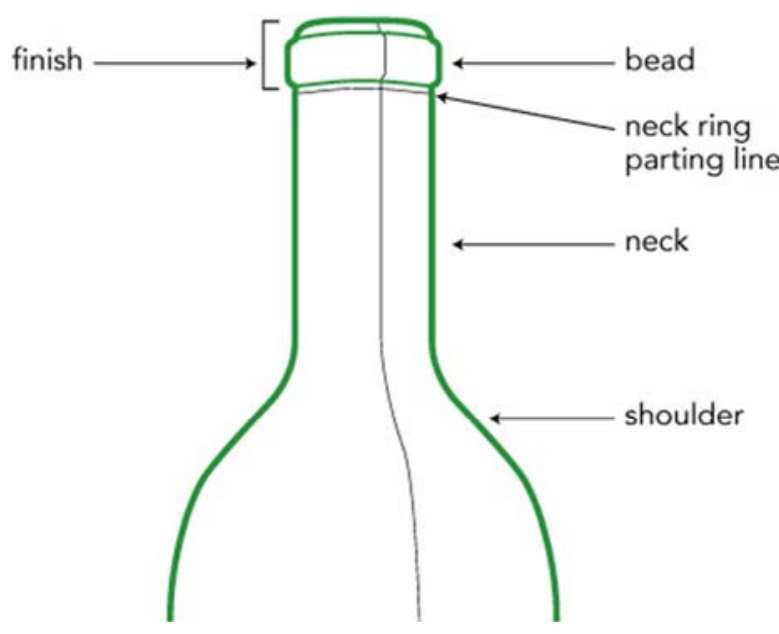

Figure 10. Seduction Wine Bottle.

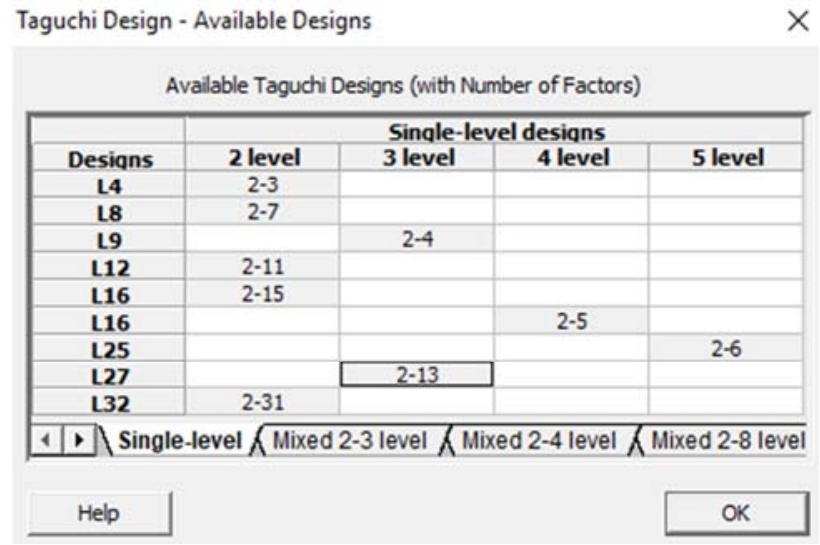

Figure 11. Available taguchi designs (with number of factors).

In the above table we can see most of the causes which are uncontrollable, undetectable and difficult to simplify are arising from the method or PROCESS, consequently in the improve phase the project will comprehend all the 
improvement methods.

\subsubsection{Improve}

Improving Castle bottle Uneven Glass Distribution

There are different methods for optimization of a glass making process. Some researches paraphrased the methodology used for optimization in similar sectors. Taguchi technique, nonlinear modeling, artificial neural network (ANN), response surface modeling, genetic algorism
(GA), and fuzzy logic are some of them.

From the above methodologies/tools DOE/Taguchi technique is supportive and more widely applicable in the glass making process.

To analyze the effects of factors on the output these procedures have to be used.

Developing suitable design

Checking feasibility:

Table 6. Process degree of freedom.

\begin{tabular}{|c|c|c|c|}
\hline Factors & Levels & DOF, N-1 & Process DOF \\
\hline Molten glass temperature $(\mathrm{Co})$ & 3 & 2 & \multirow{4}{*}{8} \\
\hline Machine speed (Cuts/Min) & 3 & 2 & \\
\hline Counter blow timing (Sec) & 3 & 2 & \\
\hline Gob temperature $(\mathrm{Co})$ & 3 & 2 & \\
\hline
\end{tabular}

\section{Run the design:}

\begin{tabular}{|c|c|c|c|c|}
\hline \multirow{2}{*}{ Run } & \multicolumn{4}{|l|}{ Control Factors } \\
\hline & Glass Temp $\left({ }^{\circ} \mathrm{C}\right)$ & Machine Speed (cuts/min) & Gob Temp $\left({ }^{\circ} \mathrm{C}\right)$ & Counter Blow Timing (Sec) \\
\hline 1 & 1200 & 26 & 800 & 3 \\
\hline 2 & 1200 & 26 & 800 & 3 \\
\hline 3 & 1200 & 26 & 800 & 3 \\
\hline 4 & 1200 & 30 & 900 & 5 \\
\hline 5 & 1200 & 30 & 900 & 5 \\
\hline 6 & 1200 & 30 & 900 & 5 \\
\hline 7 & 1200 & 34 & 1000 & 7 \\
\hline 8 & 1200 & 34 & 1000 & 7 \\
\hline 9 & 1200 & 34 & 1000 & 7 \\
\hline 10 & 1400 & 26 & 900 & 7 \\
\hline 11 & 1400 & 26 & 900 & 7 \\
\hline 12 & 1400 & 26 & 900 & 7 \\
\hline 13 & 1400 & 30 & 1000 & 3 \\
\hline 14 & 1400 & 30 & 1000 & 3 \\
\hline 15 & 1400 & 30 & 1000 & 3 \\
\hline 16 & 1400 & 34 & 800 & 5 \\
\hline 17 & 1400 & 34 & 800 & 5 \\
\hline 18 & 1400 & 34 & 800 & 5 \\
\hline 19 & 1600 & 26 & 1000 & 5 \\
\hline 20 & 1600 & 26 & 1000 & 5 \\
\hline 21 & 1600 & 26 & 1000 & 5 \\
\hline 22 & 1600 & 30 & 800 & 7 \\
\hline 23 & 1600 & 30 & 800 & 7 \\
\hline 24 & 1600 & 30 & 800 & 7 \\
\hline 25 & 1600 & 34 & 900 & 3 \\
\hline 26 & 1600 & 34 & 900 & 3 \\
\hline 27 & 1600 & 34 & 900 & 3 \\
\hline
\end{tabular}

\section{Collect the result}

\begin{tabular}{llllll}
\hline \multirow{2}{*}{ Run } & Control Factors & & & Counter Blow Timing \\
\cline { 2 - 6 } & Glass Temp & Machine Speed & Gob Temp & 3 & 5.32 \\
\hline 1 & 1200 & 26 & 800 & 3 & 4.03 \\
2 & 1200 & 26 & 800 & 3 & 2.42 \\
3 & 1200 & 26 & 800 & 5 & 3.22 \\
4 & 1200 & 30 & 900 & 5 & 2.78 \\
5 & 1200 & 30 & 900 & 5 & 3.11 \\
6 & 1200 & 30 & 1000 & 7 & 2.63 \\
7 & 1200 & 34 & 1000 & 7 & 3.15 \\
8 & 1200 & 34 & 1000 & 7 & 4.11 \\
9 & 1200 & 34 & 900 & 7 & 3.98 \\
10 & 1400 & 26 & 900 & 7 & 3.8 \\
11 & 1400 & 26 & 900 & 7 & 3.21 \\
12 & 1400 & 26 & 1000 & 3 & 3.42 \\
13 & 1400 & 30 & 1000 & 3 & 3.48 \\
14 & 1400 & 30 & 1000 & 3 & \\
15 & 1400 & 30 & & 79 & \\
\hline
\end{tabular}




\begin{tabular}{llllll}
\hline \multirow{2}{*}{ Run } & Control Factors & & & & Counter Blow Timing \\
\cline { 2 - 5 } & Glass Temp & Machine Speed & Gob Temp & Result \\
\hline 16 & 1400 & 34 & 800 & 5 & 4.49 \\
17 & 1400 & 34 & 800 & 5 & 4.11 \\
18 & 1400 & 34 & 800 & 5 & 3.98 \\
19 & 1600 & 26 & 1000 & 5 & 3.8 \\
20 & 1600 & 26 & 1000 & 5 & 3.21 \\
21 & 1600 & 26 & 1000 & 5 & 3.22 \\
22 & 1600 & 30 & 800 & 7 & 2.78 \\
23 & 1600 & 30 & 800 & 7 & 3.11 \\
24 & 1600 & 30 & 800 & 7 & 5.26 \\
25 & 1600 & 34 & 900 & 3 & 4.03 \\
26 & 1600 & 34 & 900 & 3 & 2.42 \\
27 & 1600 & 34 & 900 & 3 & 3.22 \\
\hline
\end{tabular}

Analyze the main effects:

By using MINITAB 16 the mean effect is analyzed. The analysis also demonstrates the rank of each control factor by considering the response output value.

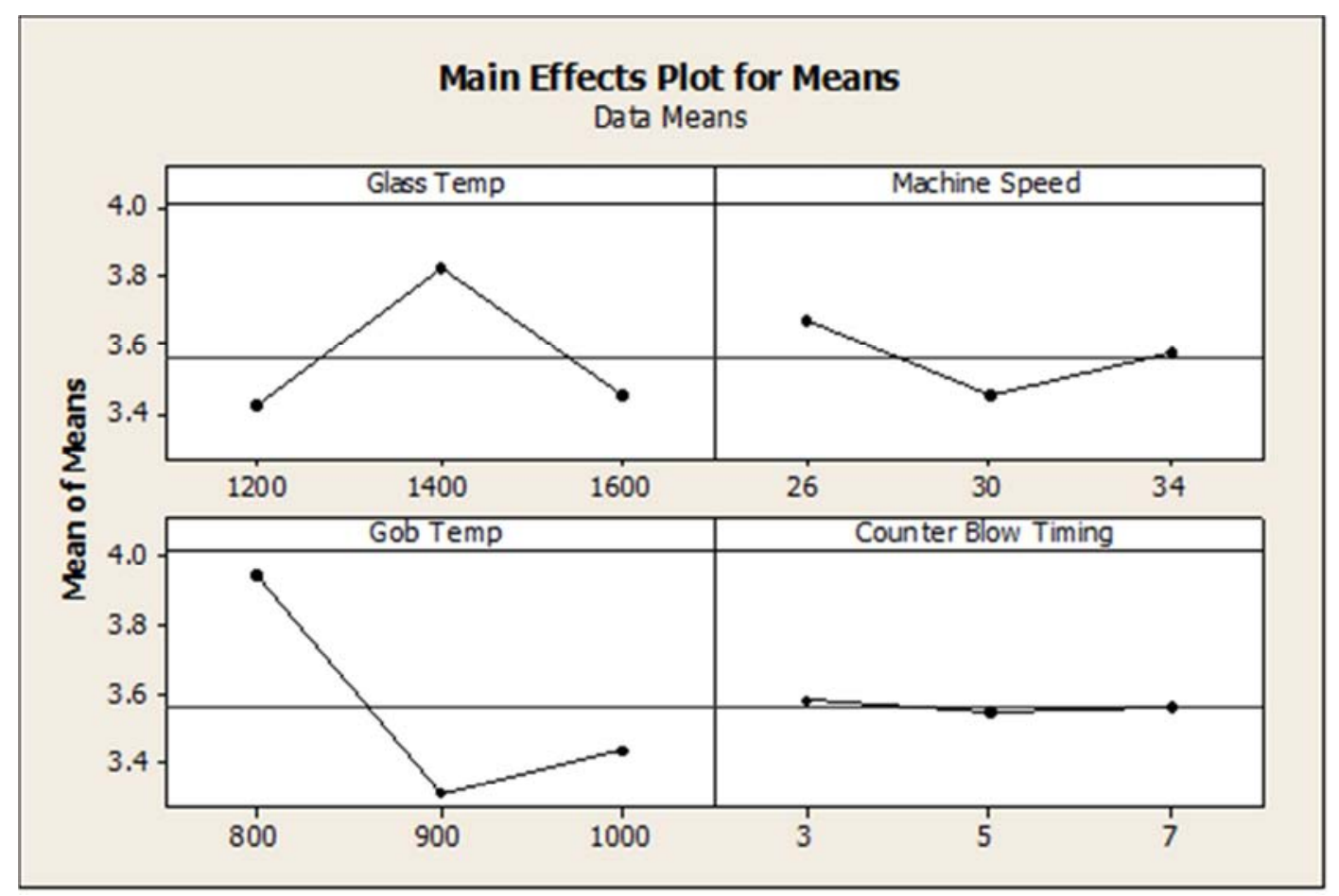

Figure 12. Main effects plot for mean.

Finding the optimum values

Table 7. Response Table for Signal to Noise Ratios Nominal is best $\left(10^{*} \log 10\left(\right.\right.$ Ybar $\left.\left.* * 2 / s^{* * 2}\right)\right)$.

\begin{tabular}{lllll}
\hline Level & Glass Temp & Machine Speed & Gob Temp & Counter Blow Timing \\
\hline 1 & 14.64 & 15.96 & 13.81 & 14.55 \\
2 & 22.04 & 18.08 & 17.89 & 22.17 \\
3 & 13.65 & 16.3 & 18.63 & 13.61 \\
Delta & 8.39 & 2.11 & 4.82 & 8.56 \\
Rank & 2 & 4 & 3 & 1 \\
\hline
\end{tabular}

Table 8. Response Table for Means.

\begin{tabular}{lllll}
\hline Level & Glass Temp & Machine Speed & Gob Temp & Counter Blow Timing \\
\hline 1 & 3.419 & 3.666 & 3.944 & 3.581 \\
2 & 3.818 & 3.45 & 3.308 & 3.547 \\
3 & 3.45 & 3.571 & 3.434 & 3.559 \\
Delta & 0.399 & 0.216 & 0.637 & 0.034 \\
Rank & 2 & 3 & 1 & 4 \\
\hline
\end{tabular}


Table shows the rank of each control factor by considering their delta value. From sound to noise ratios table for Counter Blow Timing, Glass Temperature, Gob Temperature and Machine speed has a higher impact on glass distribution from high to low respectively.

Therefore, the optimum parameters for the selected product are Counter blow timing (5 sec, level 2), Glass Temperature $\left(1400^{\circ} \mathrm{C}\right.$, level 2$)$, Gob Temperature $\left(1000^{\circ} \mathrm{C}\right.$, level 3), and Machine speed (30 cuts/min, level 2). Now we can conclude that this setup is an optimum for the selected product type even if the selected parameter is not in trial run.

Using the same procedure and steps here is the result for the second selected type of product (seduction poor diameter)

Therefore, the optimum parameters for the selected product are Size of funnel diameter (3.5 inch level 3), Counter blow pressure (2.75 bar, level 3), Plunger contact timing (2 sec, level 1), and final blow timing (6 sec, level 2). Now we can conclude that this setup is an optimum for the selected product type even if the selected parameter is not in trial run.

From sound to noise ratios table for size of funnel diameter, counter blow pressure, Plunger contact timing and final blow timing has a higher impact on seduction product bead diameter from high to low respectively.

\subsubsection{Control}

Yes/No diagram (in some way similar with Boolean diagram) is needed for operational purpose. The diagram below shows sequence of activities that the operators to follow when he face a respective problem related to uneven glass distribution.

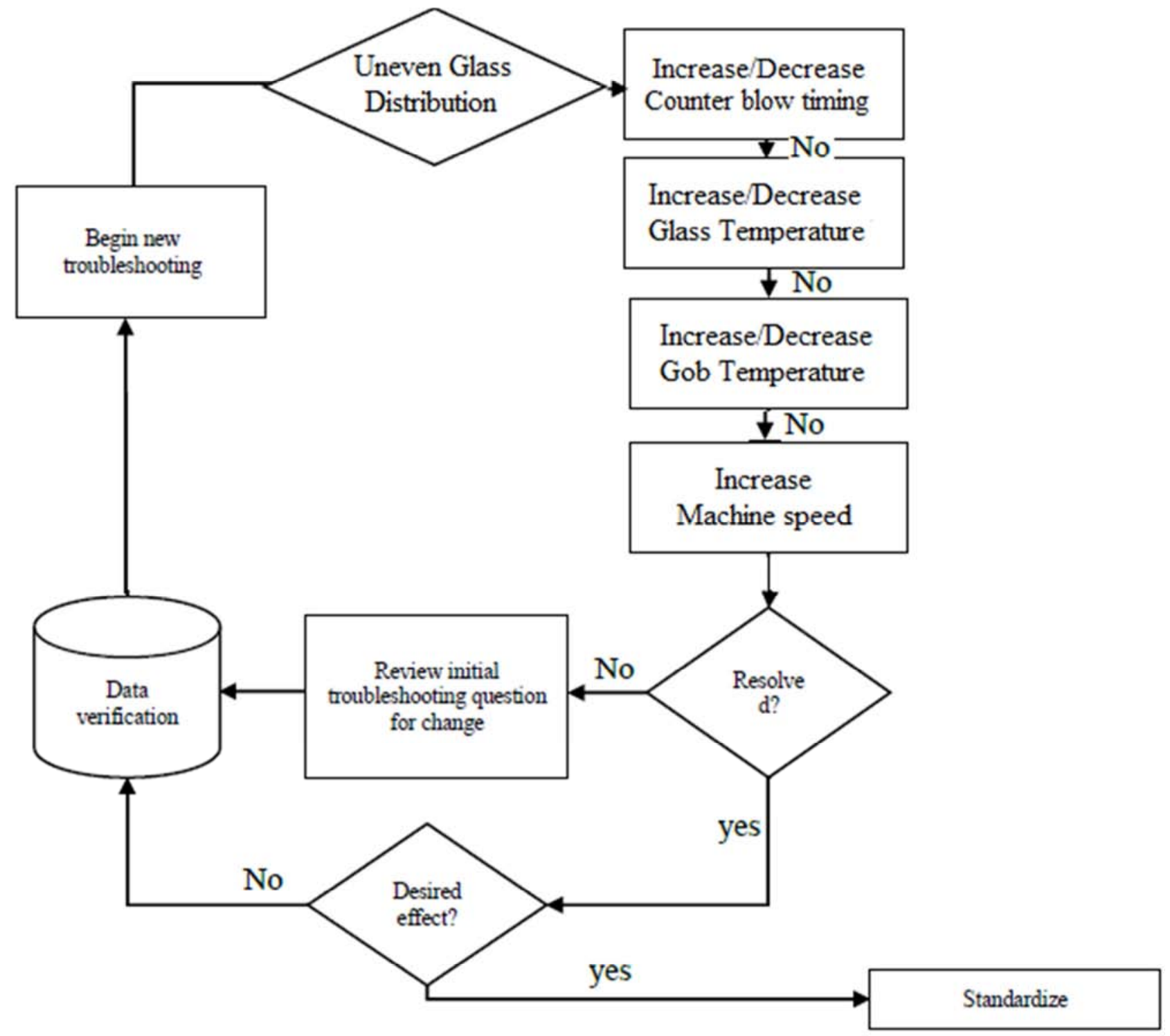

Figure 13. Yes/No diagram as a control mechanism for Uneven Glass Distribution.

The above figure shows the remedial action that should be taken when uneven glass distribution problem occurs. 


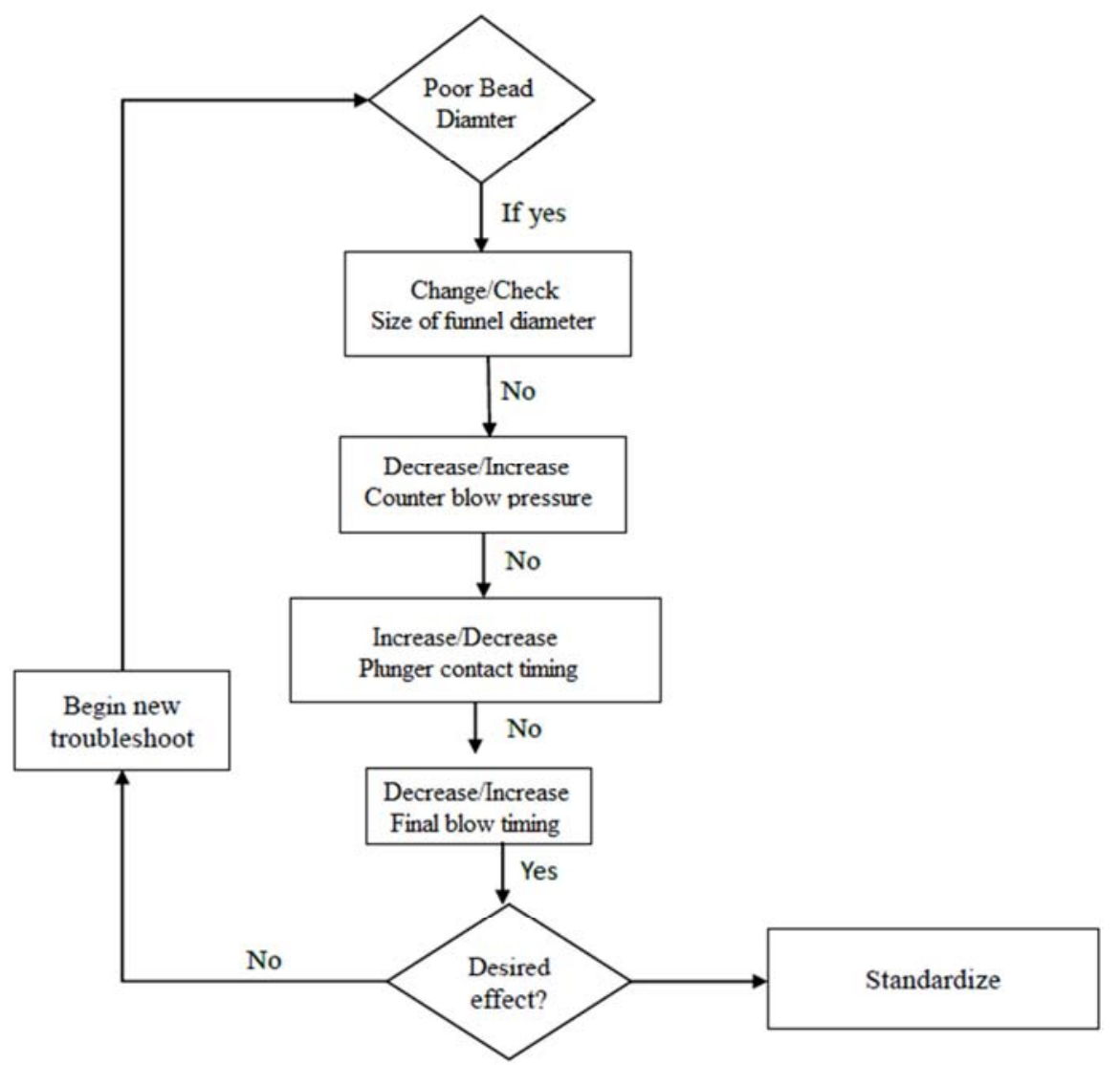

Figure 14. Yes/No diagram as a control mechanism for poor bead diameter.

After selecting the optimum value for the process, testing and collecting result is necessary. At the improve phase the optimum values for the factors are identified. Based on these values the process is run and data collected to verify either the values are really reducing the defect amount or not. To do so preparation and set up time is essential to check the effects. To minimize the challenge of set up time, the runs are conducted continually by changing the parameters in orderly fashion. As a result, data is collected to see the effect of change in parameter after 120 minutes in case of Seduction and 90 Minutes for Castle products. The countermeasures which are prepared at improve phase has implemented and got remarkable results.

Table1 9. Result of glass distribution in castle products after Optimization.

\begin{tabular}{|c|c|c|c|c|c|c|c|}
\hline Runs & Factor & Set Value & Result (mm) & Runs & Factor & Set Value & Result \\
\hline 1 & Counter blow timing & $5 \mathrm{sec}$, level 2 & 3.12 & 23 & Counter blow timing & $5 \mathrm{sec}$, level 2 & 3.05 \\
\hline 2 & Glass Temperature & $1400^{\circ} \mathrm{C}$, level 2 & 3.22 & 24 & Glass Temperature & $1400^{\circ} \mathrm{C}$, level 2 & 3.22 \\
\hline 3 & Gob Temperature & $1000^{\circ} \mathrm{C}$, level 3 & 3.02 & 25 & Gob Temperature & $1000^{\circ} \mathrm{C}$, level 3 & 3.11 \\
\hline 4 & Machine speed & 30 cuts/min, level 2 & 2.98 & 26 & Machine speed & 30 cuts/min, level 2 & 3.20 \\
\hline 5 & & & 2.94 & 27 & & & 3.28 \\
\hline 6 & & & 3.15 & 28 & & & 2.98 \\
\hline 7 & & & 2.93 & 29 & & & 2.94 \\
\hline 8 & & & 3.05 & 30 & & & 3.15 \\
\hline 9 & & & 3.23 & 31 & & & 3.18 \\
\hline 10 & & & 3.00 & 32 & & & 2.89 \\
\hline 11 & & & 2.89 & 33 & & & 3.15 \\
\hline 12 & & & 3.11 & 34 & & & 2.84 \\
\hline 13 & & & 3.00 & 35 & & & 3.00 \\
\hline 14 & & & 2.99 & 36 & & & 2.98 \\
\hline 15 & & & 3.15 & 37 & & & 3.28 \\
\hline 16 & & & 3.2 & 38 & & & 3.2 \\
\hline 17 & & & 3.18 & 39 & & & 3.13 \\
\hline 18 & & & 3.2 & 40 & & & 3.15 \\
\hline 19 & & & 2.96 & 41 & & & 2.99 \\
\hline 20 & & & 2.99 & 42 & & & 3.23 \\
\hline 21 & & & 3.3 & 43 & & & 2.93 \\
\hline 22 & & & 3.28 & 44 & & & 3.15 \\
\hline
\end{tabular}


Based on the above table it is possible to compare its minimum and maximum glass distribution thickness amount with the before improvement same amount. Before improvement the minimum and the maximum thickness found were 0.9413 and 6.57 and now after the improvement has been implemented the minimum and maximum glass distribution thickness amount is 2.84 and 3.28 respectively.

Table 10. Result of bead diameter in mm for seduction production after Optimization.

\begin{tabular}{|c|c|c|c|c|c|c|c|}
\hline Runs & Factor & Set Value & Result (mm) & Runs & Factor & Set Value & Result \\
\hline 1 & Size of funnel diameter & 3.5 inch level 3 & 28.3 & 13 & Size of funnel diameter & 3.5 inch level 3 & 28.53 \\
\hline 2 & Counter blow pressure & 2.75 bar, level 3 & 28.62 & 14 & Counter blow pressure & 2.75 bar, level 3 & 28.95 \\
\hline 3 & Plunger contact timing & $2 \mathrm{sec}$, level 1 & 28.43 & 15 & Plunger contact timing & 2 sec, level 1 & 28.64 \\
\hline 4 & final blow timing & $6 \mathrm{sec}$, level 2 & 28.92 & 16 & final blow timing & $6 \mathrm{sec}$, level 2 & 28.61 \\
\hline 5 & & & 28.58 & 17 & & & 28.86 \\
\hline 6 & & & 28.56 & 18 & & & 28.57 \\
\hline 7 & & & 28.63 & 19 & & & 28.92 \\
\hline 9 & & & 28.64 & 21 & & & 28.85 \\
\hline 10 & & & 28.68 & 22 & & & 28.84 \\
\hline 11 & & & 28.56 & 23 & & & 28.39 \\
\hline 12 & & & 28.37 & 24 & & & 28.51 \\
\hline
\end{tabular}

The same to castle bottle production the above table can compare its minimum and maximum bead diameter with the before improvement same amount. Before improvement the minimum and the maximum bead diameter found were 28.11 and 29.78 and now after the improvement has been implemented the minimum and maximum glass distribution thickness amount is 28.43 and 28.95 respectively.

Sigma level calculation after optimization

From 25 ton pull by the furnace throughout $24 \mathrm{hrs}$ and changing this parameter to gram 45,454 Pcs of bottles are produced within the production line in one full day. And after the optimization is implemented the defect percentage for the Product Seduction Wine and castle is $15 \%$ meaning that 6,818 unit is defective from the whole product.

Product Amount per day $=45,454$ bottles

Defect $=15 \%=6,818$ Psc

Opportunity $=3$ (pre-analytical, analytical, and postanalytical phases)

Defect Per Opportunity (DPO)

$$
\begin{gathered}
\mathrm{DPO}=\frac{\text { Defect }}{\text { Product } * \text { Opportunities }} \\
=\frac{6818}{45,454 * 3} \\
=0.05
\end{gathered}
$$

Defect Per Million Opportunities (DPMO)

$$
\begin{gathered}
(\mathrm{DPMO})=\frac{\text { Defect }}{\text { Product } * \text { Opportunities }} * 10^{6} \\
=\frac{6818}{45,454 * 3} * 10^{6} \\
=50,000
\end{gathered}
$$

\subsection{Numerical Examination}

Using six sigma table as a reference and by interpolation the company sigma level lies at 3.1 after optimization is identified and implemented.

Cost Determination

\section{Before Optimization}

Manufacturing cost $/$ gram $=0.05$ cents

$45 \%$ defective/day

No of defective bottles before optimization $=20,454.3$ bott/day

Average weight for both products $=420 \mathrm{gr} / \mathrm{bottle}$

$=20,454.3 * 420 * 0.05$

$=429,540.3$ Birr/day

After Optimization

$15 \%$ defective/day

No of defective bottles before optimization $=6,818$ bott $/$ day

Average weight for both products $=420 \mathrm{gr} /$ bottle

$=6,818 * 420 * 0.05$

$=143,178$ Birr/day

Difference

429,540.3 Birr/day - 143,178 Birr/day=286,362.3 Birr/day

\section{Discussion, Conclusion and Recommendation}

\subsection{Discussion}

In the entire research as DMAIC approach is the scientific approach for reducing the deviations and improving the capability levels of the manufacturing processes, the five steps in a DMAIC project represent a structured roadmap used to improve existing processes. As similar as the objective stated by Sharma and Rao, DMAIC methodology is a very systematic approach that provides a pathway to go to the roots of the problems gives opportunities for improvement and starts by defining the problem as shown in the this research through formation of focus group to select the critical defect types to give more emphasis and therefore there are ten mainly discussed types of defects were identified. During prioritizing of defects FMEA has been used in order to rank which type of defect has high possibility for improvement.

According to Schroeder's simple terms, Six Sigma quality performance means 3.4 defects per million opportunities 
(accounting for a 1.5-sigma shift in the mean) and also According to Kaushik using process capability analysis, the DPMO level the sigma level of the engine mounting bracket (EMB) hole diameter rejection were known, similarly in this research 149,997.8 defects per million opportunities have been measured, which accounts for 2.5 sigma level.

Affirms that when we look at Six Sigma as a methodology, there are many models available for process improvements like DMADV, DMAIC, Breakthrough strategy, Eckes method, Six Sigma Roadmap, IDOV, and DMEDI. The most widely used models are DMAIC and DMADV. Similarly in this research the DMAIC model is used since a product is in existence but is not meeting the customer requirements [16]. And therefore by taking those grounds Six Sigma DMAIC was selected as an appropriate methodology to deal with in this study.

A research conducted by [18] for the analysis of the process in six sigma tools used a detailed process map and a fish-bone diagram. Equivalently this research has made an argument on the models to be used throughout the analysis part and decided to use fishbone diagram and to show the root causes for defects. Similarly another tool used in this phase was criteria matrix which has tried to select and go on to specific source of problem

Identified possible solutions by brainstorming and constructing a counter measure matrix. Nevertheless in this research Taguchi design of experiment was used as an improvement tool, from the analysis to get the optimal operating point for Size of funnel diameter, Counter blow pressure, Plunger contact timing and final blow timing for poor bead diameter of seduction wine bottle and Counter blow timing, Glass Temperature, Gob Temperature and Machine speed in the case of uneven glass distribution for castle product [3].

\subsection{Conclusion}

The result obtained from the model is observable and notable. Controlling mechanism is devised to sustain the obtained results. It witnesses that the model is compatible for defect reduction activities as well as for other similar improvement ideas. It strengthens the cooperation sprit among departments; build capacity to challenge a problem which occurred in the work place. Moreover, as the model drives to use different industrial quality tools it upgrades the knowledge and also increases the reliability of the work.

Using DMAIC- defines measure, analyze, improve, and control model we can reduce defects in practical pattern. And also, alike the improvement achieved in case of bringing the company's sigma level from 2.5 to 3.5 , the research has got an accomplishment in terms of poor quality cost reduction from $45 \%$ of defective products per day which is accountable for $429,540.3 \mathrm{birr} /$ day to $15 \%$ defective products per day which means 143,178 . Birr/day. In general speaking a $30 \%$ of minimization of defective products and saving of $286,362.3$ birr/day has been achieved. Therefore, we can say DMAIC model well-suits for defect reduction activity in glass production industries if appropriate tools are selected and utilized for each phase.

\subsection{Recommendation}

Though this study minimize cost of poor quality by reducing defects and get remarkable results using DMAIC model, it doesn't mean that this model is the only way to attack the defect for the comings. Due to the scope and limitation of the research some issues didn't include in this work and needs further investigation. So that for the person who have an interest on reduction of defect or DMAIC model introduction it is better to consider the following points for superior results:

1) As the study only focused on Furnace and IS machine, introducing the model on the defects created on Annealing Lehr can be an area of interest.

2) Due to its defect share the paper selected Seduction and Castle bottles alone, but it is possible to reduce defects of other bottle types i.e. Meta 302, Ambo 402, beer 292 and Areke 602 by using similar model.

3) The paper has focused on the process side of the system. One can investigate the role of machines and manpower on making of defect intensively.

4) As Glass is recyclable by its nature, the effect of recycled raw material in making of defect can be a new area for defect reduction project.

\section{References}

[1] Adnan Rafik Khan, L. Z., 2011. Applying Six Sigma in Software Companies for Process Improvement. Review of Management, 1 (2), pp. 21-34.

[2] Bargerstock, A. S. \& Richards, S. R., 2015. Improving business processes in higher education through DMAIC. Case Study: Application of DMAIC to Academic Assessment in Higher Education. $A S Q, 6$ (2), pp. 31-40.

[3] Desai, D. A., Kotadiya, P. \& Makwana, N., 2015. Curbing variations in packaging process through Six Sigma way in a large-scale food-processing industry. $J$ IndEngInt, 11, pp. $119-129$.

[4] Gijo, E. V., Scaria, J. \& Antony, J., 2011. Application of six sigma methodology to reduce defects of a grinding process, Quality and Reliability Engineering International, 27 (8), pp. $1221-1234$.

[5] James R. Evans, W. M. L., 2005. An Introduction to Six sigma and Process Improvement.

[6] Kabir, E., Boby, S. M. M. I. \& Lutfi, M., 2013. Productivity Improvement by using Six-Sigma.

[7] Mijajlevski, A., 2013. The six sigma dmaic methodology in logistics. In Logistics international conference. pp. 227-232.

[8] Mikel Harry, R. S., 2000. Six Sigma.

[9] Pyzdek, T., 2003. The Six Sigma Handbook, McGraw Hill.

[10] Schroeder, R. G. et al., 2008. Six Sigma: Definition and underlying theory §. Journal of Operations Management, 26, pp. 536-554. 
[11] Sharma, G. V. S. S. \&Rao, P. S., 2014. A DMAIC approach for process capability improvement an engine crankshaft manufacturing process. Journal of Industrial Engineering International, 10 (65), pp. 1-11.

[12] Shokri, A., Nabhani, F., \& Bradley, G. (2015). Reducing the scrap rate in an electronic manufacturing SME through Lean Six Sigma methodology: An Action Research. IEEE Engineering Management Review. https://doi.org/10.1109/EMR.2019.2931184.

[13] Stephen, P., 2004. Application of DMAIC to integrate Lean Manufacturing and Six Sigma. Virginia Polytechnic Institute and State University.

[14] Yadav, A., \& Sukhwani, V. K. (2016). Quality Improvement by using Six Sigma DMAIC in an Industry. 6 (6), 41-46.
[15] Yadav, N., Mathiyazhagan, K., \& Kumar, K. (2019). Application of Six Sigma to minimize the defects in the glass manufacturing industry: A case study. Journal of Advances in Management Research, 16 (4), 594-624. https://doi.org/10.1108/JAMR-11-2018-0102.

[16] Yasin, A., 2014. Application of Lean Six Sigma for Process Improvement: the Case of Ethiopian Paper and Pulp S. C. (June).

[17] Zhang, W. et al., 2009. Six Sigma: A Retrospective and Prospective Study Six Sigma: A Retrospective and Prospective Study. POMS.

[18] Kumar, S. \& Sosnoski, M., 2009. Using DMAIC Six Sigma to systematically improve shopfloor production quality and costs. International Journal of Productivity and Performance Management, 58 (3), pp. 254-273. 